\title{
Olfactory Discrimination in Adult Male Rats Undernourished during the Pre- and Neonatal Period
}

\author{
Mitzi G. Carreon, Carmen Torrero, Mirelta Regalado, Lorena Rubio, Manuel Salas \\ Developmental Neurobiology and Neurophysiology Department, Neurobiology Institute, University of Mexico, Campus \\ UNAM Juriquilla, Queretaro, Mexico \\ Email: masal@unam.mx
}

Received June 9, 2012; revised July 7, 2012; accepted July 16, 2012

\begin{abstract}
In the neonatal rat, the olfactory system is a fundamental channel to locate and recognize the mother, to survive and develop early social behavior, and to distinguish related or unrelated members of a litter. Perinatal undernutrition in rats alters the neuronal organization and functioning of the olfactory system and its ascending relays, possibly affecting odor discrimination. In this study we compared the frequency and time spent visiting the source of urine obtained from unrelated female subjects and amyl acetate odors vs water in adult perinatally underfed rats. Each test initiated with one daily presentation during three consecutive aliquots of deionized water $(10 \mu l)$ placed on a filter paper for 2 min, separated by 1-min intervals for habituation. The water presentations were followed by three exposures to an odor, all at the same dilution (either 1:1 or 1:80) for dishabituation. Control (C) and undernourished (U) subjects display similar, significant habituation/dishabituation responses, except that the $\mathrm{U}$ subjects showed greater increases in the frequency and duration of visits to undiluted and diluted urine and amyl acetate cues compared to the controls. These findings are similar to previous studies showing that adult rats investigate novel odors longer than the familiar ones. Thus, perinatal undernutrition appears to interfere with the foundation of the olfactory development causing long-term olfactory discrimination deficits as revealed by the increased frequency and duration of visits to the source of odors that may be relevant for social behavior.
\end{abstract}

Keywords: Olfactory Discrimination; Main Olfactory System; Perinatal Undernutrition

\section{Introduction}

In altricial animals like the rat, neonatal food intake mainly depends on olfactory and gustatory environmental signals during early mother-litter interactions that permit the learning nipple attachment by rat pups that are unable to execute coordinated movements, to see or to hear until the second week of life [1-3]. In the newborn rat the nipple attachment to the mother is prenatally initiated when the foetus is exposed to the amniotic fluid components, and after birth when the mother spreads the saliva material on its ventrum to facilitate nipple attachment and milk ingestion [4-6]. When ear and eye-opening occur and motor activities improves, the olfactory learning associated with maternal odor expands and the maternal or the environmental olfactory stimuli become paired with tactile, auditory and visual cues outside the nest to promote olfactory experience throughout the pre-weaning period and thereafter in adult social interactions $[4,7,8]$. During the pre-weaning period the precocious physiological ability of newly born rats is concurrent with a notorious anatomical and functional immatur- ity of the olfactory channel (e.g. glomeruli, mitral/tufted output cells, granule neurons, amygdala nuclei, etc.) that nevertheless seems to be sufficient for early olfactory discrimination for survival [3,9-12].

In the rat undernourishment throughout gestation and/ or suckling provokes delayed sensory maturation and permanent central nervous system (CNS) alterations, including the cerebral cortex, amygdala, hippocampus and the nucleus of the solitary tract [13-17]. Additionally, neonatal undernutrition decreases the total neonatal area of the olfactory bulb (OB), reduces the glomeruli size, and causes poor dendritic development of mitral cells, with few changes in the perikarya measurements [10]. These alterations are associated with prolonged OB postdischarges elicited by electrical stimulation, suggesting that granule neurons that modulate mitral discharges are also affected $[16,18,19]$. There is clear evidence of olfactory anatomical alterations associated to perinatal undernutrition; however, it is not known whether these alterations interfere with odor discrimination in long-term olfactory-guided behavior.

In this study we evaluate the olfactory ability of male 
adult Wistar rats that had been perinatally underfed; we found that these rats were less able than controls to discriminate unrelated urine and amyl acetate vs water, which may correlate with the olfactory neuronal relay alterations commonly seen in early starved rats.

\section{Methods}

\subsection{Animals}

Experiments were approved by Local Animal Committees and comply with the Guide for the Care and Use of Laboratory Animals (NIH). Subjects were female Wistar rats (Rattus norvegicus) bred from a laboratory stock maintained at the Institute of Neurobiology University of Mexico, which derived from a stock from Harlan Sprague-Dawley (Indianapolis, IN, USA). Animals were maintained in a 12/12-h light/dark cycle under standard regulated conditions of temperature $24^{\circ} \mathrm{C} \pm 2{ }^{\circ} \mathrm{C}$, humidity (45\% - 50\%) and with food (Purina chow) and water ad libitum. For mating groups of six females with two males $(200-250 \mathrm{~g})$ per experimental condition were housed in standard, translucent plastic cages $(60 \times 50 \times$ $\left.20 \mathrm{~cm}^{3}\right)$. Sperm positive females were placed individually in plastic maternity cages $\left(50 \times 40 \times 20 \mathrm{~cm}^{3}\right)$ with wood shavings as nesting material. The day after birth (day 1 of age), pups from different litters were weighed and sexed, and four females and four males from each litter were randomly distributed among dams in order to minimize genetic and nutritional differences and to give them similar probability of development.

\subsection{Control Group (CG)}

This group consisted of 24 adult male rats obtained from 6 well-nourished litters, nursed by well-fed dams with free access to food (Purina chow) and water throughout the gestation. After birth, $\mathrm{CG}$ rats were fed by interchanging a pair of normally lactating females (one of them with a sham nipple ligature) every $12 \mathrm{~h}$ (at 0800 and 20:00 h) between the litters as described elsewhere [12]. This experimental paradigm permits adequate nursing of pups and care given by the mother (body licking, retrieving, anogenital stimulation, crouching position over the pups, etc.), when the mothers were interchanged between litters [20]. This experimental paradigm attenuates the effects of sensory deprivation that commonly accompanies similar underfeeding methods [21].

\subsection{Undernourished Group (UG)}

This group contained 24 adult male rats obtained from 6 different litters. The dams were undernourished during the gestational period. Thus, from G6 - G12 mothers where fed with $50 \%(7.8 \mathrm{~g})$ of the standard diet (Purina chow) that receive a normal pregnant rat; from G13 G18 with 60\% (10.9 g), and from G19 - G21 with 100\% $(15.6 \mathrm{~g})$ of the same diet until parturition to avoid re-absorption of the fetus or cannibalism by the dam [12]. The standard diet contains lipids (59.81\%), carbohydrates $(12.3 \%)$, and proteins $(28.04 \%)$; L-lysine represents $1.42 \%$ of the diet, an amount that surpasses the normal $1.38 \%$ nutritional requirement for the rat. The normal diet for an adult female rat was calculated to contain $89.31 \mathrm{kcal}$ per day. The calorific content calculated for this diet was $89.31 \mathrm{kcal}$ per day for a normal adult diet. This feeding schedule was chosen because most of the OB neurogenesis occurred prenatally [22]. After birth, prenatally undernourished pups were nursed for $12 \mathrm{~h}$ by a normal lactating mother and $12 \mathrm{~h}$ by a subcutaneously nipple ligated foster dam, interchanged every $12 \mathrm{~h}$ between litters from postnatal days $1-24$. Animals from both groups were weighed at 1, 5, 12, 20 and 30 days of age to evaluate the effects of dietary treatments on neonatal physical development, and again at 87 , 92, 99, and 102 days of age to determine if long-term body weight differences were still present during the behavioral testing. Weaning was at day 25 of age, followed by free access to water and a balanced diet.

\subsection{Odor Exposure}

Olfactory discrimination tests started on day 87 of age, using urine obtained from litters of unrelated females (four adult female rats that were between proestrus or estrus) subjects submitted to the same dietary conditions in order to motivate and discard the effects of diet to the olfactory discrimination of males [23,24]. In any case urine from lactating females was used. Two or three days before the experiment the urine donors were gently manipulated by the experimenter for $5 \mathrm{~min}$ to minimize the effects of stress and habituate them to the recording chamber [25]. Thereafter, urine was collected by holding the rat and gently massaging its lower abdomen until drops of urine were released. Urine was obtained with the aid of a pipette and dropped into a glass tube to obtain samples not contaminated with fecal matter. The urine was collected in tubes using a funnel, and were pooled and mixed by vortexing, $100 \mu \mathrm{l}$ aliquots of urine were stored at $-20^{\circ} \mathrm{C}$ until the day of use. Before the behavioral testing session ach aliquot of urine was thawed for $30 \mathrm{~min}$ and dilutions prepared 1:1 (undiluted) and 1:80 ( $1 \mu \mathrm{l}$ of urine $+79 \mu \mathrm{l}$ of water) by using deionized water. Similarly two dilutions of amyl acetate (AA) (1:1 and 1:80) were also prepared. All olfactory discrimination tests were performed between 1000 and $1300 \mathrm{~h}$, beginning with the exposure to urine, followed by amyl acetate, and the next day the odors were presented in reverse order. This procedure attempts to counterbalance 
a possible stimulus order effect that may influence the results.

Subjects were transported in a plastic box $(40 \times 50 \times$ $20 \mathrm{~cm}^{3}$ ) without bedding or food and placed into a sound proof camera kept in darkness with red light illumination $(60 \mathrm{~W})$, and separated from the ambient noise of the main laboratory. After a $3 \mathrm{~min}$, of no-odour adaptation period, the subject was handled for $30 \mathrm{sec}$ and then placed in the center of a plastic transparent box $(40 \times 20 \times$ $20 \mathrm{~cm}^{3}$ ). The stainless steel cage top was removed and replaced with a clean top equipped with a wire mesh barrier located against the grid bars of the empty food hopper. Odor cues were presented by pipetting $10 \mu \mathrm{l}$ of one of the dilutions of urine or AA onto a $5 \mathrm{~cm} 2$ piece of filter paper that was taped to a plastic piece $(4.5 \times 4.5$ $\mathrm{cm}^{2}$ ), placed against the wire mesh screen in the food hopper so that volatile odors from the stimulus were available at body level. Subjects were unable to make physical contact with the filter paper using either their snout or paws [26]. The stimulation protocol consisted of a habituation phase with 3 consecutive deionized water (W) presentations ( 2 min each) separated by an intertrial interval of $1 \mathrm{~min}$; thus was followed by a dishabituation phase of 3 consecutive ( 2 min each) undiluted or diluted olfactory cues separated by a $1 \mathrm{~min}$ intertrial intervals. An odor discrimination response was recognized when the subject placed its nose against the grid bars opposite the plastic containing the urine spot. In all cases the test session was recorded with a video system, and the following measurements were made: The subject's frequency of visits and the number of seconds the subject spent investigating the odor stimulus during the 2-min span exposure. It was not expected that the behavioral testing modify the body weight of subjects however, to evaluate the long-term effects of perinatal undernourishment on the physical growth of the subjects, at the end of the session the body weight of CG and UG animals was noted.
Data were analyzed using the Systat Statistical software v.11.0. To evaluate score differences between dietary treatments and olfactory cue presentations at different dilutions, the following separate statistical comparisons were used: 1) values for neonatal body weight differences were compared using a two-way ANOVA, 2 (nutritional regimes) $\times 5$ (ages); and 2 (nutritional regimes) $\times 4$ (ages) and during the adult stage of animals; 2) the scores differences of frequency of visits and time spent investigating the olfactory stimulus between the third $\mathrm{W}$ testing and the first odor cue presentation were compared using a nonparametric two-tailed within-groups Wilcoxon test; 3) to display the responses of different groups and odors the differences between the 3 average consecutive $\mathrm{W}$ control exposures vs the 3 average consecutive $\mathrm{C}$ and $\mathrm{U}$ olfactory cue presentations of each dilution, were compared using a one-way ANOVA; 4) to analyze the olfactory discrimination of $U$ rats we compared the $\mathrm{W}$ control scores vs the undiluted or diluted odors in $U$ rats by using a two-way ANOVA, 2 (W control vs U subjects) $\times 3$ (exposures). A probability of $p \leq$ 0.05 was considered statistically significant.

\section{Results}

The ANOVA comparisons of body weight in the neonatal rats indicated that body weight of $U$ subjects were significantly reduced compared to the controls, $\mathrm{F}(1,10)=$ 547.72, $\mathrm{p}<0.0001$; they change with age, $\mathrm{F}(4,40)=$ $3340, \mathrm{p}<0.0001$, and a significant interaction diet by age, $\mathrm{F}(4,40)=77.38, \mathrm{p}<0.0001$ was obtained. Adult body weight differences were also significantly reduced in the $\mathrm{U}$ rats, $\mathrm{F}(1,10)=83.80, \mathrm{p}<0.0001$; modified by age, $\mathrm{F}(3,30)=21.93, \mathrm{p}<0.0001$, and a significant interaction diet by age, $\mathrm{F}(3,30)=14.05, \mathrm{p}<0.0001$ was also observed (Table 1). The post hoc analyses on each day of the study in both $\mathrm{C}$ and $\mathrm{U}$ neonatal and adult subjects are shown in Table 1.

Table 1. Body weight (in grams \pm SEM) of pups reared by control and perinatally underfed dams $(n=6)$.

\begin{tabular}{|c|c|c|c|c|c|c|c|}
\hline \multirow{2}{*}{ Age (Days) } & \multicolumn{3}{|c|}{ Neonatal } & \multirow{2}{*}{ Age (Days) } & \multicolumn{3}{|c|}{ Adult } \\
\hline & Control & & Undernourished & & Control & & Undernourished \\
\hline 1 & $6.56 \pm 0.15$ & & $6.06 \pm 0.15 \mathrm{NS}$ & 87 & $307.00 \pm 6.57$ & & $206.60 \pm 6.96^{\mathbf{V}}$ \\
\hline 5 & $10.75 \pm 0.21$ & & $8.26 \pm 0.12^{\boldsymbol{\nabla}}$ & 92 & $296.80 \pm 5.12$ & & $227.20 \pm 9.00^{\boldsymbol{\nabla}}$ \\
\hline 12 & $24.36 \pm 0.27$ & & $14.46 \pm 0.18^{\boldsymbol{\nabla}}$ & 99 & $306.20 \pm 3.80$ & & $230.60 \pm 7.38^{\nabla}$ \\
\hline 20 & $34.31 \pm 1.16$ & & $23.36 \pm 0.24^{\boldsymbol{\nabla}}$ & 102 & $312.60 \pm 3.61$ & & $244.60 \pm 7.75^{\nabla}$ \\
\hline 30 & $75.63 \pm 1.26$ & & $56.76 \pm 0.46^{\boldsymbol{\nabla}}$ & & & & \\
\hline Factor & $\mathrm{df}$ & $\mathrm{F}$ & $\mathrm{p}<$ & & df & $\mathrm{F}$ & $\mathrm{p}<$ \\
\hline (A) Nutrition & 1,10 & 547.72 & $0.0001^{\mathbf{V}}$ & & 1,10 & 83.80 & $0.0001^{\mathbf{V}}$ \\
\hline (B) Age & 4,40 & 3340.11 & $0.0001^{\mathbf{V}}$ & & 3,30 & 21.93 & $0.0001^{\mathbf{V}}$ \\
\hline $\mathrm{A} \times \mathrm{B}$ & 4,40 & 77.38 & $0.0001^{\boldsymbol{\nabla}}$ & & 3,30 & 14.05 & $0.0001^{\boldsymbol{\nabla}}$ \\
\hline
\end{tabular}

$\boldsymbol{\nabla}_{p}<0.05$, Fisher LSD test. NS $=$ Nonsignificant values. 
Statistical comparisons between the third W exposure of habituation and the first undiluted or diluted odor exposure indicated that both groups increase significantly $(p<0.05)$ their frequency of visits to the undiluted $(1: 1)$ female urine although the $U$ subject exhibited a higher increase $(\mathrm{p}<0.05)$ than the $\mathrm{C}$ group (Figure 1(a)). Furthermore, when the AA undiluted (1:1) was presented a similar significant increase in the frequency of visits $(\mathrm{p}<$ 0.05 ) for both $\mathrm{C}$ and $\mathrm{U}$ subjects occurred (Figure 1(b)).

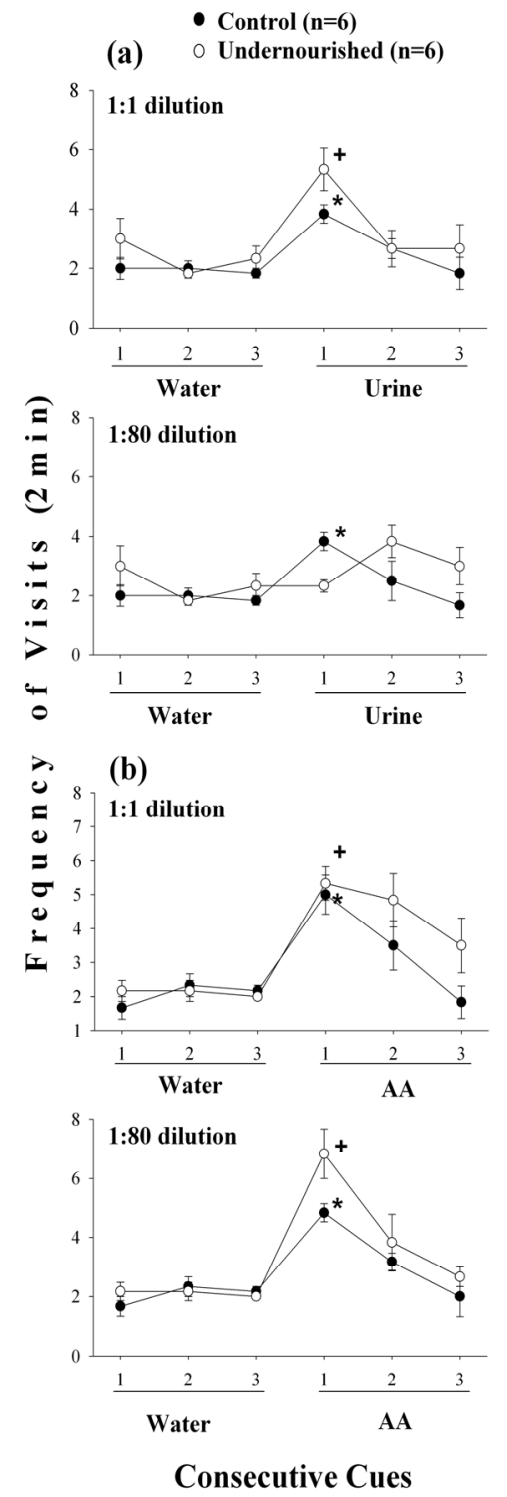

Figure 1. Mean \pm SEM of the frequency of visits to undiluted and diluted urine (a), and AA (b) odor cues following three consecutive exposures to $W$ in $C$ and $U$ adult male rats. Significant comparisons $(p<0.05)$ between the third $W$ and the first odor cue exposure (Wilcoxon test) in control (*) and undernourished $(+)$ rats; $n=6$, number of subjects included in each experimental group. Note the dishabituation in $\mathrm{C}$ and $\mathrm{U}$ subjects in the first odor exposure, and high values for $\mathrm{U}$ rats in the habituation trials 2 and 3.
The frequency of visits when the female urine was diluted (1:80) did not indicate significant changes for the $\mathrm{U}$ subjects, while the $\mathrm{C}$ rats increased significantly their frequency of visits $(p<0.05)$, but in both groups the frequency of visits was reduced when compared to the undiluted (1:1) urine odor (Figure 1(a)). The frequency of visits to the diluted AA (1:80) odor exhibited significant increase $(p<0.05)$ in both $C$ and $U$ rats and very similar to the undiluted AA, the increase was higher for $U$ than for $\mathrm{C}$ subjects (Figure 1(b)).

The time spent investigating the undiluted urine showed significant increases $(p<0.05)$ compared to the water stimulus in both $\mathrm{C}$ and $\mathrm{U}$ animals, but the increase was smaller in the $U$ group of rats (Figure 2(a)). Following the third water presentation there was a slight, but significant increase $(\mathrm{p}<0.05)$ in the time spent investigating the diluted urine odor only in the $U$ group of rats, but was small compared to the response produced by the undiluted urine (Figure 2(a)). The U subjects spent significantly more time $(\mathrm{p}<0.05)$ investigating the undiluted AA stimulus but in the $\mathrm{C}$ group the increase $(\mathrm{p}<$ $0.05)$ was only one third as great as that for undiluted urine (Figure 2(b)). The time investigating the diluted AA odor showed significant $(\mathrm{p}<0.05)$ increases in the $\mathrm{C}$ and $U$ groups of animals, with a higher increase in the $U$ subjects, similar to the response of the $\mathrm{C}$ group to undiluted urine (Figure 2(a)).

The ANOVA comparisons of the three accumulated consecutive water presentations versus the three consecutive odor exposures measuring either the frequency of visits, or the time spent investigating the stimulus, at the two odor dilutions indicated that the $\mathrm{C}$ and $\mathrm{U}$ group exhibited significant increases $(p<0.05)$ when exposed to urine and AA compared to animals exposed to water (Figures 3(a) and (b)). In most of the cases the U subjects showed greater increases in the number of visits and the time spent investigating both dilutions of the AA odor, compared to the $\mathrm{C}$ group of subjects.

Table 2 presents the ANOVA comparisons of responses obtained in the three consecutive $\mathrm{W}$ controls and $\mathrm{U}$ group to different odor cues and dilutions.

\section{Discussion}

The present findings indicate that perinatal undernourishment in the adult rat resulted in general in olfactory discrimination deficiencies as revealed in the adult stage by the increased frequency of visits, and the time investigating two dilutions of urine and AA compared with the response to water. These deficiencies were accompanied by low body weight effects that were not related to the olfactory discrimination tests instead, they reflected long-term effects due the interference of perinatal food restriction, neonatal stress and maternal deprivation with 


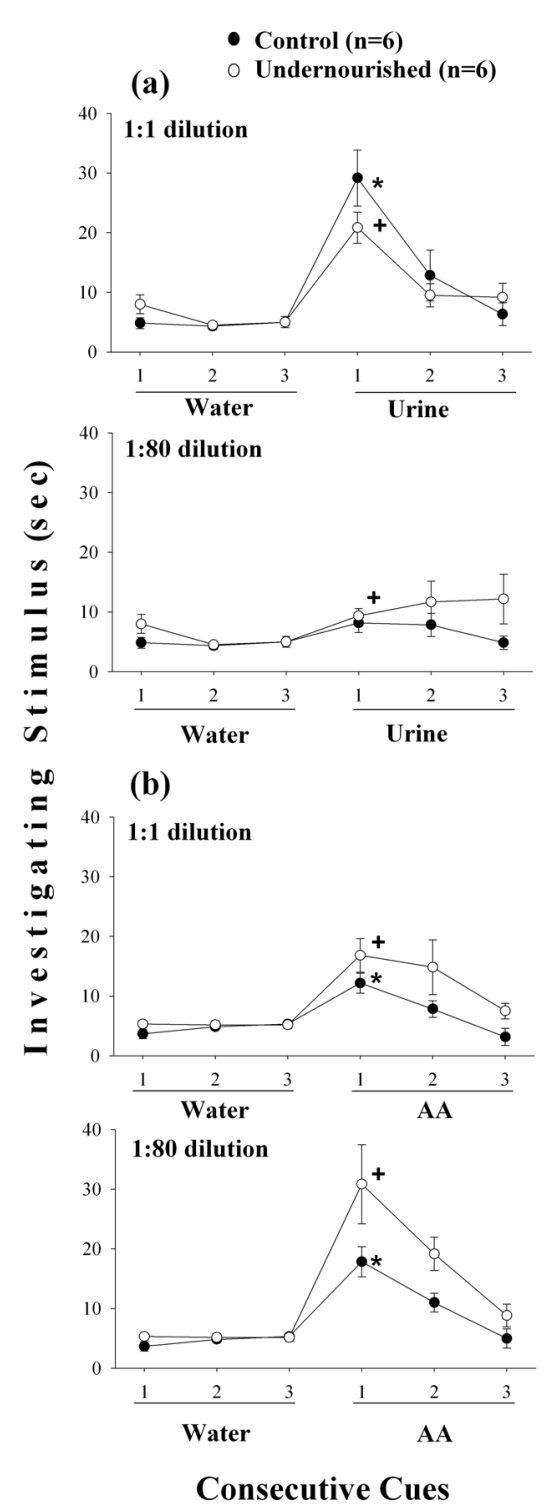

Figure 2. Mean \pm SEM values of the time spent investigating undiluted and diluted urine (a) and AA (b) odor cues after three consecutive exposures to $W$ in $C$ and $U$ adult male rats. Significant comparisons $(p<0.05)$ of the third $W$ value vs the first odor cue exposure (Wilcoxon test) in control (*) and undernourished $(+)$ rats; $n=6$ subjects included in each experimental group. Note the dishabituation in $\mathbf{C}$ and $U$ subjects in the first odor exposure, and high values for $U$ animals in habituation trials 2 and 3.

development of the hypothalamic pituitary axis [27-31].

In response to undiluted or diluted urine and AA odor stimuli, both $\mathrm{C}$ and $\mathrm{U}$ subjects exhibited similar increases followed by an inconsistent habituation, in the frequency of visits and the time investigating the first stimulus, the values of both parameters were higher for the perinatally underfed subjects, except with the diluted urine. In the $U$ subjects call the attention the lack of significant response in the frequency of visits to the diluted urine compared to
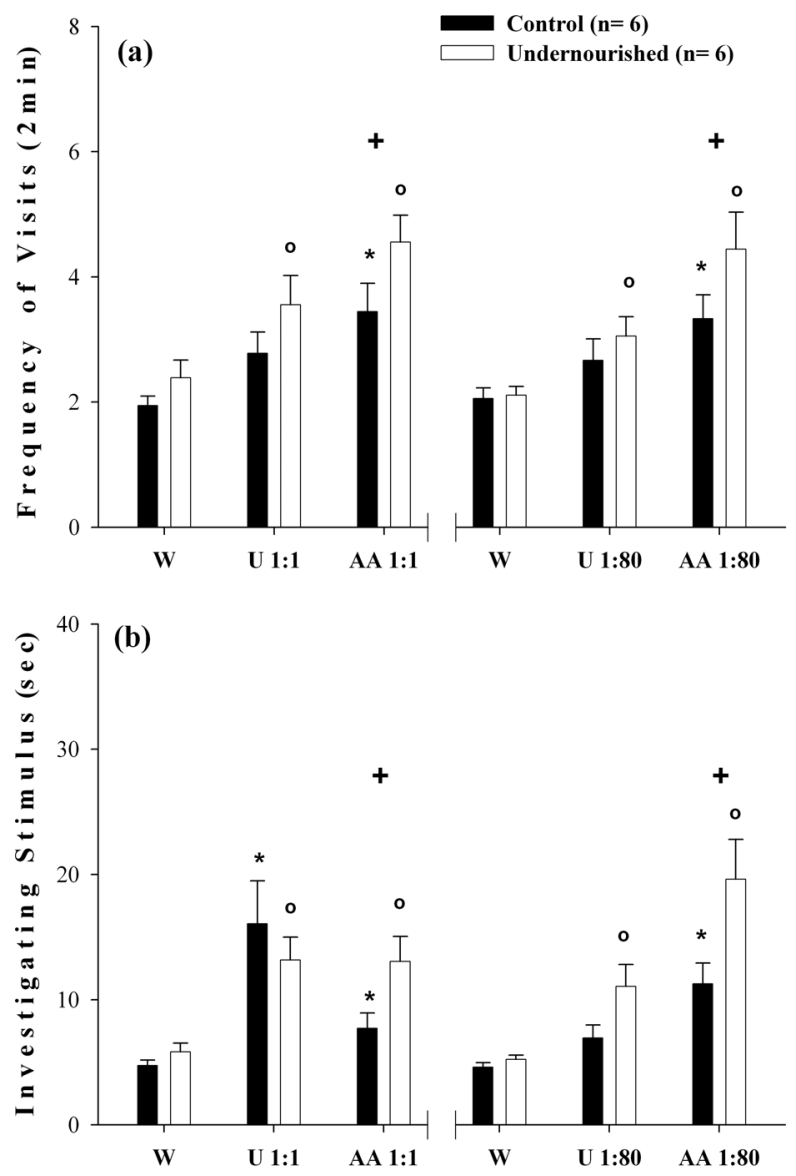

Figure 3. Mean \pm SEM values of three days accumulated data of $W$, and undiluted and diluted urine and AA odors. In (a), ANOVA comparisons of the frequency of visits per 2-min interval to three consecutive $W$ cues vs the three undiluted and diluted urine and AA olfactory cues. In (b), ANOVA analyses of the time investigating the three consecutive $W$ exposures vs the three undiluted and diluted urine and AA odors. Note the increased frequency and investigation times of the $U$ subjects in response to the undiluted and diluted AA odors. (o) Significant comparisons $(p<0.05)$ between $W$ scores in $U$ subjects. (*) Significant comparisons $(p<0.05)$ between $W$ scores in $C$ subjects. $(+)$ Significant comparisons $(p<0.05)$ between $C$ and $U$ subjects in each exposure.

the $\mathrm{W}$, while both $\mathrm{C}$ and $\mathrm{U}$ groups exhibit a clear significant increase in the duration of visits to the undiluted urine with respect to the $\mathrm{W}$ but without significant differences between them. Furthermore, these effects were consistently higher in the subjects exposed to undiluted and diluted AA (Figure 1(a)). These findings suggest that the urine cue was less efficient than AA in evoking dishabituation, possibly because the urine odor is a common component in the context of the home-cage environment whereas the AA odor represents a very strong and novel environmental stimulus. In this regard, the deficiencies of the underfed subjects expressing habituation following the first odor presentation is in line 
Table 2. ANOVA comparisons of exposures to control $W$ versus the undiluted and diluted urine and AA cues in olfactory discrimination of undernourished adult rats.

\begin{tabular}{|c|c|c|c|c|c|c|c|c|c|}
\hline \multirow{4}{*}{ Factors } & \multicolumn{9}{|c|}{ Frequency of visits } \\
\hline & \multicolumn{5}{|c|}{$\underline{\text { Urine }}$} & \multicolumn{4}{|c|}{$\underline{\text { Amyl acetate }}$} \\
\hline & \multicolumn{3}{|c|}{$1: 1$} & \multicolumn{2}{|c|}{$1: 80$} & \multicolumn{2}{|c|}{$1: 1$} & \multicolumn{2}{|c|}{$1: 80$} \\
\hline & $\mathrm{df}$ & $\mathrm{F}$ & $\mathrm{p}<$ & $\mathrm{F}$ & $\mathrm{p}<$ & $\mathrm{F}$ & $\mathrm{p}<$ & $\mathrm{F}$ & $\mathrm{p}<$ \\
\hline (A) Nutrition & 1,10 & 9.71 & $0.010^{\boldsymbol{}}$ & 6.45 & $0.029^{\boldsymbol{\nabla}}$ & 49.39 & $0.0001^{\boldsymbol{\nabla}}$ & 45.09 & $0.0001^{\top}$ \\
\hline (B) Stimulus & 2,20 & 7.29 & $0.004^{\boldsymbol{\nabla}}$ & 2.97 & NS & 0.97 & NS & 4.38 & $0.026^{\nabla}$ \\
\hline \multirow[t]{2}{*}{$\mathrm{A} \times \mathrm{B}$} & 2,20 & 6.44 & $0.006^{\boldsymbol{\nabla}}$ & 2.87 & NS & 1.95 & NS & 7.68 & $0.003^{\boldsymbol{\nabla}}$ \\
\hline & \multicolumn{9}{|c|}{ Investigation time } \\
\hline (A) & 1,10 & 22.32 & $0.0008^{\boldsymbol{}}$ & 4.79 & $0.050^{\boldsymbol{}}$ & 29.91 & $0.0002^{\boldsymbol{\nabla}}$ & 28.56 & $0.0003^{\mathbf{\top}}$ \\
\hline (B) & 2,20 & 11.64 & $0.0004^{\boldsymbol{\nabla}}$ & 0.64 & NS & 1.42 & NS & 7.29 & $0.004^{\boldsymbol{\top}}$ \\
\hline $\mathrm{A} \times \mathrm{B}$ & 2,20 & 11.04 & $0.0005^{\boldsymbol{\nabla}}$ & 0.71 & NS & 2.57 & NS & 9.71 & $0.001^{\boldsymbol{\nabla}}$ \\
\hline
\end{tabular}

$\nabla_{p}<0.05$, two-way ANOVA test. NS = Nonsignificant values.

with previous studies suggesting that the perinatal undernutrition interferes with the CNS mechanisms underlying the habituation processes with long-term consequences for olfactory discrimination $[12,32,33]$. Another possibility could be related to the long-timescale olfactory paradigm used here to provoke the olfactory dishabituation [34,35]. This paradigm with long olfactory cue exposures $(2 \mathrm{~min})$ and inter-trial intervals of $1 \mathrm{~min}$ may evoke in the $U$ subjects a persistent dishabituation processes after the novel olfactory stimulus presentations suggesting a deficient inhibitory mechanism; giving support to this possibility is the observation that in the hippocampus and amygdala of perinatally underfed rats, both the number and the dendritic density of multipolar neurons are reduced $[15,16]$.

Another point of interest concerns the effects of perinatal undernutrition on brain functioning during the preweaning period that provoke long-term damage in adulthood. Thus, fasting during the perinatal period unavoidably interfere with the mother litter-bonds by inducing a poor maternal responsiveness that disrupts the pups' olfactory bulb plasticity (reduced olfactory glomerulus profiles, mitral/tufted output, and number of granule cells) with neuronal hypoplasia of the amygdaloid complex and hippocampal neurons; these characteristics may be the anatomical basis for long-term deficiencies in the olfactory discrimination $[10,11,36-39]$. This proposal is also consistent with studies on early mother-litter interference using olfactory stimuli that are either separate or paired with different sensorial cues, which demonstrate how neonatal experience can improve pups' survival, stress maturation, and learning in the nest environmental context $[9,40-43]$.
The current study also provides information concerning the long-term effects of early perinatal undernutrition on the olfactory discrimination of adult rats after they resume a normal diet. The current data indicated that after water habituation, perinatal underfed rats increased both the frequency and the duration of visits to the source of both undiluted and diluted urine and AA odor cues, particularly in the case of the diluted AA, the underfed subjects may require additional exposure to odors compared to the controls in order to attain the same olfactory discrimination response. These findings are consistent with several studies showing that adult rats and gerbils investigate novel odors longer than familiar odors [44, 45]. Thus, the constant daily exposure of the members of a litter to urine in the nest environment may result in a persistent habituation, occasionally interrupted by novel environmental odor influences. This could be a case of a long-term deficiency associated with perinatal undernutrition. In this case, perinatal undernutrition may be associated with a long-term deficiency of the regulatory mechanisms underlying the habituation processes provoked by the AA odors that increase the dishabituation responses in the $U$ group of rats. In addition, prolonged olfactory bulb post-discharges are elicited by OB electrical stimulation, and may be related to a significant reduction in the number of granule inhibitory neurons of olfactory structures that integrate and modulate mitral discharges, this reduction underlies deficits in the olfactory-guided behaviors of perinatally underfed rats $[11,18,19,46,47]$. However, studies are needed to analyze the effects of perinatal undernutrition on the number and morphological alterations of granule, mitral and tufted cells, and on olfactory discrimination of familiar and unfamiliar odors in adulthood. 


\section{Conclusion}

We conclude that perinatal food restriction interferes with the anatomical and functional organization of BO and olfactory relays, resulting in long-term deficiencies in odor discrimination and possibly with the expression of the olfactory-guided social behavior.

\section{Acknowledgements}

The study was partly supported by DGAPA/UNAM, IN207307-3. We thank Dr. D. Pless for editorial assistance and suggestions.

\section{REFERENCES}

[1] W. S. Small, "Notes on the Psychic Development of the Young White Rat," American Journal of Psychology, Vol. 11, No. 1, 1899, pp. 80-100. doi:10.2307/1412730

[2] D. A. Callison and J. W. Spencer, "Effect of Chronic Undernutrition and/or Visual Deprivation upon the Visual Evoked Potential from the Developing Rat Brain," Developmental Psychobiology, Vol. 1, No. 3, 1968, pp. 196204. doi: $10.1002 /$ dev. 420010308

[3] M. Salas, S. Schapiro and C. Guzman-Flores, "Development of Olfactory Bulb Discrimination between Maternal and Food Odors," Physiology and Behavior, Vol. 5, No. 1, 1970, pp. 1261-1264. doi:10.1016/0031-9384(70)90037-5

[4] M. H. Teicher and E. M. Blass, "First Suckling Response of the Newborn Albino Rat: The Roles of Olfaction and Amniotic Fluid," Science, Vol. 198, No. 4317, 1977, pp. 635-636. doi:10.1126/science.918660

[5] R. Coopersmith and L. Leon, "The Neurobiology of Early Olfactory Learning,” In: E. M. Blass, Ed., Developmental Psychobiology and Behavioral Ecology, Plenum Press, New York, 1988, pp. 283-308. doi:10.1007/978-1-4684-5421-5 8

[6] C. Raineki, A. Pickenhagen, T. L. Roth, D. M. Babstock, J. H. McLean, C. W. Harley, A. B. Lucion and R. M. Sullivan, "The Neurobiology of Infant Maternal Odor Learning," Brazilian Journal of Medical and Biological Research, Vol. 43, No. 10, 2010, pp. 914-919. doi:10.1590/S0100-879X2010007500090

[7] C. Nyakas and E. Endroczi, "Olfaction-Guided Approaching Behavior of Infantile Pups to the Mother in a Maze Box," Acta Physiologica Academiae Scientiarum Hungaricae, Vol. 38, No. 1, 1970, pp. 59-65.

[8] R. M. Sullivan, D. A. Wilson, R. Wong, A. Correa and M. Leon, "Modified Behavioral and Olfactory Bulb Responses to Maternal Odors in Preweanling Rats," Brain Research, Developmental Brain Research, Vol. 53, No. 2, 1990, pp. 243-247. doi:10.1016/0165-3806(90)90013-O

[9] S. Moriceau and R. M. Sullivan, "Maternal Presence Serves as a Switch between Learning Fear and Attraction in Infancy," Nature Neuroscience, Vol. 9, No. 8, 2006, pp. 1004-1006. doi:10.1038/nn1733

[10] C. Frias, C. Torrero, M. Regalado and M. Salas, "Organization of Olfactory Glomeruli in Neonatally Under- nourished Rats," Nutritional Neuroscience, Vol. 9, No. 1-2, 2006, pp. 49-55. doi:10.1080/10284150500506042

[11] C. Frias, C. Torrero, M. Regalado and M. Salas, "Development of Mitral Cells and Olfactory Bulb Layers in Neonatally Undernourished Rats," Nutritional Neuroscience, Vol. 12, No. 3, 2009, pp. 96-104. doi:10.1179/147683009X423238

[12] M. Ruiz-Diaz, C. Torrero, M. Regalado and M. Salas, "Perinatal Undernourishment and Handling: Effects on Olfactory Discrimination in the Newborn Rat," Nutritional Neuroscience, Vol. 13, No. 5, 2010, pp. 196-204. doi:10.1179/147683010X12611460764408

[13] B. G. Cragg, "The Development of Cortical Synapses during Starvation in the Rat," Brain, Vol. 95, No. 1, 1972, pp. 143-150. doi:10.1093/brain/95.1.143

[14] M. Salas, "Effects of Early Undernutrition on Dendritic Spines of Cortical Pyramidal Cells in the Rat," Developmental Neuroscience, Vol. 3, No. 3, 1980, pp. 109-117. doi:10.1159/000112384

[15] C. Escobar and M. Salas, "Neonatal Undernutrition and Amygdaloid Nuclear Complex Development: An Experimental Study in the Rat," Experimental Neurology, Vol. 122, No. 2, 1993, pp. 311-318. doi:10.1006/exnr.1993.1130

[16] J. P. Andrade, M. D. Madeira and M. M. Paula-Barbosa, "Evidence of Reorganization in the Hippocampal Mossy Fiber Synapses of Adult Rats Rehabilitated after Prolonged Undernutrition," Experimental Brain Research, Vol. 104, No. 2, 1995, pp. 249-261. doi:10.1007/BF00242011

[17] L. Rubio, C. Torrero, M. Regalado and M. Salas, "Alterations in the Solitary Tract Nucleus of the Rat Following Perinatal Food Restriction and Subsequent Nutritional Rehabilitation," Nutritional Neuroscience, Vol. 7, No. 5-6, 2004, pp. 291-300. doi:10.1080/10284150400019922

[18] F. Math and J. L. Davrainville, "Electrophysiological Study on the Postnatal Development of Mitral Cell Activity in the Rat Olfactory Bulb. Influence of Undernutrition," Brain Research, Vol. 194, No. 1, 1980, pp. 223-227. doi:10.1016/0006-8993(80)91333-5

[19] K. S. Bedi, "Effects of Undernutrition during Early Life on Granule Cell Numbers in the Rat Dentate Gyrus," The Journal of Comparative Neurology, Vol. 311, No. 10, 1991, pp. 425-433. doi:10.1002/cne.903110311

[20] M. Salas, C. Torrero and S. Pulido, "Long-Term Alterations in the Maternal Behavior of Neonatally Undernourished Rats," Physiology and Behavior, Vol. 33, No. 2, 1984, pp. 273-278.

doi:10.1016/0031-9384(84)90111-2

[21] A. Lynch, "Postnatal Undernutrition: An Alternative Method," Developmental Psychobiology, Vol. 9, No. 1, 1976, pp. 39-48. doi:10.1002/dev.420090107

[22] L. Rosselli-Austin and J. Altman, "The Postnatal Development of the Main Olfactory Bulb of the Rat," Journal of Developmental Physiology, Vol. 1, No. 4, 1979, pp. 295-313.

[23] K. Lydell and R. L. Doty, "Male Rat Odor Preferences for Female Urine as a Function of Sexual Experience, Urine 
Age, and Urine Source," Hormones and Behavior, Vol. 3, No. 3, 1972, pp. 205-212. doi:10.1016/0018-506X(72)90033-5

[24] R. E. Brown, H. M. Schellinck and A. M. West, "The Influence of Dietary and Genetic Cues on the Ability of Rats to Discriminate between the Urinary Odors of MHCCongenic Mice," Physiology and Behavior, Vol. 60, No. 2, 1996, pp. 365-372. doi:10.1016/S0031-9384(96)80006-0

[25] C. Zalaquett and D. Thiessen, "The Effects of Odors from Stressed Mice on Conspecific Behavior," Physiology and Behavior, Vol. 50, No. 1, 1991, pp. 221-227. doi:10.1016/0031-9384(91)90524-R

[26] M. J. Baum and E. B. Keverne, "Sex Difference in Attraction Thresholds for Volatile Odors from Male and Estrous Female Mouse Urine," Hormones and Behavior, Vol. 41, No. 2, 2002, pp. 213-219. doi:10.1006/hbeh.2001.1749

[27] C. M. Khun, S. R. Butler and S. M. Schanberg, "Selective Depression of Serum Growth Hormone during Maternal Deprivation in Rat Pups," Science, Vol. 201, No. 4360, 1978, pp. 1034-1036. doi:10.1126/science.684424

[28] C. Wimpfheimer, E. Saville, M. J. Voirol, E. Danforth Jr. and A. G. Burger, "Starvation-Induced Decreased Sensitivity of Resting Metabolic Rate to Triiodothyronine," Science, Vol. 4412, No. 205, 1979, pp. 1272-1273. doi: $10.1126 /$ science. 224460

[29] G. E. Evoniuk, C. M. Kuhn and S. M. Schanberg, "The Effect of Tactile Stimulation on Serum Growth Hormone and Tissue Ornithine Decarboxylase Activity during Maternal Deprivation in Rat Pups," Communications in Psychopharmacology, Vol. 3, No. 5, 1979, pp. 363-370.

[30] S. M. Schanberg, G. E. Evoniuk and C. M. Kuhn, "Tactile and Nutritional Aspects of Maternal Care: Specific Regulators of Neuroendocrine Function and Cellular Development," Proceedings of the Society for Experimental Biology and Medicine, Vol. 175, No. 2, 1984, pp. 135-146.

[31] J. M. Ketelslegers, D. Maiter, M. Maes, L. E. Underwood and J. P. Thissen, "Nutritional Regulation of the Growth Hormone and Insulin-Like Growth Factor-Binding Proteins," Hormone Research, Vol. 45, No. 3-5, 1996, pp. 252-257. doi:10.1159/000184797

[32] B. M. Lester, R. E. Klein and S. J. Martinez, "The Use of Habituation in the Study of the Effects of Infantile Malnutrition," Developmental Psychobiology, Vol. 8, No. 6, 1975, pp. 541-546. doi:10.1002/dev.420080611

[33] D. A. Wilson and M. Leon, "Abrupt Decrease in Synaptic Inhibition in the Postnatal Rat Olfactory Bulb," Developmental Brain Research, Vol. 430, No. 1, 1987, pp. 134138. doi:10.1016/0165-3806(87)90183-0

[34] N. Mandairon, C. Stack, C. Kiselycznyk and C. Linster, "Broad Activation of the Olfactory Bulb Produces LongLasting Changes in Odor Perception," Proceedings of the National Academy of Sciences of the United States of America, Vol. 103, No. 36, 2006, pp. 13543-13548. doi:10.1073/pnas.0602750103

[35] A. M. McNamara, P. D. Magidson, C. Linster, D. A. Wilson and T. A. Cleland, "Distinct Neural Mechanisms Mediate Olfactory Memory Formation at Different Time
Scales," Learning \& Memory, Vol. 15, No. 3, 2012, pp. 117-125. doi: $10.1101 / \mathrm{lm} .785608$

[36] M. R. Rosenzweigh and E. L. Bennett, "Psychobiology of Plasticity: Effects of Training and Experience on Brain and Behavior," Behavioral Brain Research, Vol. 78, No. 1, 1996, pp. 57-65. doi:10.1016/0166-4328(95)00216-2

[37] J. H. McLean, A. Darby-King and W. S. Bonnell, "Neonatal Olfactory Sensory Deprivation Decreases BDNF in the Olfactory Bulb of the Rat," Developmental Brain Research, Vol. 128, No. 1, 2001, pp. 17-24. doi:10.1016/S0165-3806(01)00144-4

[38] F. Cirulli, L. T. Bonsignore, A. Venerosi, A. Valanzano, F. Chiarotti and E. Alleva, "Long-Term Effects of Acute Perinatal Asphyxia on Rat Maternal Behavior," Neurotoxicology and Teratology, Vol. 25, No. 5, 2003, pp. 571578. doi:10.1016/S0892-0362(03)00035-7

[39] C. A. Turner, M. H. Lewis and M. A. King, "Environmental Enrichment: Effects on Stereotyped Behavior and Dendritic Morphology," Developmental Psychobiology, Vol. 43, No. 1, 2003, pp. 20-27. doi:10.1002/dev.10116

[40] R. M. Sullivan, D. A. Wilson, C. Lemon and G. A. Gerhardt, "Bilateral 6-OHDA Lesions of the Locus Coeruleus Impair Associative Olfactory Learning in Newborn Rats," Brain Research, Vol. 643, No. 1-2, 1994, pp. 306-309. doi:10.1016/0006-8993(94)90038-8

[41] A. S. Fleming, D. H. O'Day and G. W. Kraemer, "Neurobiology of Mother-Infant Interactions: Experience and Central Nervous System Plasticity across Development and Generations," Neuroscience Biobehavioral Reviews, Vol. 23, No. 5, 1999, pp. 673-685. doi:10.1016/S0149-7634(99)00011-1

[42] A. C. Tang, "Neonatal Exposure to Novel Environment Enhances Hippocampal-Dependent Memory Function during Infancy and Adulthood," Learning and Memory, Vol. 8, No. 5, 2001, pp. 257-264. doi:10.110/1m.43101

[43] S. Macrì and H. Würbel, "Developmental Plasticity of HPA and Fear Responses in Rats: A Critical Review of the Maternal Mediation Hypothesis," Hormones and Behavior, Vol. 50, No. 5, 2006, pp. 667-680. doi:10.1016/j.yhbeh.2006.06.015

[44] E. M. Ables, L. M. Kay and J. M. Mateo, "Rats Assess Degree of Relatedness from Human Odors," Physiology and Behavior, Vol. 90, No. 5, 2007, pp. 726-732. doi:10.1016/j.physbeh.2006.12.012

[45] M. Shimozuru, T. Kikusui, Y. Takeuchi and Y. Mori, "Discrimination of Individuals by Odor in Mongolian Gerbils, Meiornes unguiculates," Zoological Science, Vol. 24, No. 5, 2007, pp. 427-433. doi:10.2108/zsj.24.427

[46] C. R. Almli, M. A. Henault, C. A. Velozo and J. P. Morgane, "Ontogeny of Electrical Activity of Main Olfactory Bulb in Freely-Moving Normal and Malnourished Rats," Developmental Brain Research, Vol. 18, No. 1-2, 1985, pp. 1-11. doi:10.1016/0165-3806(85)90245-7

[47] N. E. Cordoba M. P. Arolfo, J. D. Brioni and O. A. Orsingher, "Perinatal Undernutrition Impairs Spatial Learning in Recovered Adult Rats," Acta Physiologica Pharmacologica Therapeutic Latinoamerica, Vol. 44, No. 3, 1994, pp. 70-76. 